\title{
Synthesis and Preliminary Characterization of Octakis (Chloropropyldimethylsiloxy) Octasilsesquioxane
}

\author{
Devaney Ribeiro do Carmo ${ }^{\mathrm{a}}$, Newton Luiz Dias Filho ${ }^{\mathrm{b}}$, Nelson Ramos Stradiotto ${ }^{\mathrm{a} *}$ \\ ${ }^{a}$ Universidade Estadual Paulista, UNESP, Instituto de Química \\ PO Box 355, 14801-970 Araraquara - SP, Brazil \\ ${ }^{\mathrm{b}}$ Faculdade de Engenharia de Ilha Solteira (UNESP), Departamento de Física e Química \\ Av. Brasil Centro 56, 15385-000 Ilha Solteira - SP, Brazil
}

Received: February 13, 2003; Revised: May 4, 2004

\begin{abstract}
Octakis (hydridodimethylsiloxy) octasilsesquioxane was hydrosilated with allyl chloride using Spiers catalyst $\left(\mathrm{H}_{2} \mathrm{PtCl}_{6}\right)$. This reaction was monitored using FT-IR spectroscopy. The synthesized product was characterized by ${ }^{13} \mathrm{C},{ }^{29} \mathrm{Si}$ NMR (MAS), SEM, FT-IR, Thermogravimetric techniques. The three propyl groups $\alpha, \beta, \gamma$, (to the terminal silicon atom), associated of an allyl chloride, were clearly seen in the ${ }^{13} \mathrm{C} \mathrm{NMR}\left(\alpha-\mathrm{CH}_{2}\right.$ at $31.8 ; \beta-\mathrm{CH}_{2}$ at $37.7 ; \gamma-\mathrm{CH}_{2}$ at $\left.50.1 \mathrm{ppm}\right)$. In addition, the ${ }^{29} \mathrm{Si}$ NMR spectrum of the final product, exhibits three $\mathrm{Q}$ signals for $\mathrm{Q}$ type silicon attributed to $\mathrm{Q}^{2}(-90.1) \mathrm{Q}^{3}$ (-100.2) and $\mathrm{Q}^{4}$ (-111.3ppm). The presence of allyl chloride substitutes in octameric cube confers a relative porosity and thermal stability to the material.
\end{abstract}

Keywords: Octakis (chloropropyldimethylsiloxy) octasilsesquioxane, spherosiloxane

\section{Introduction}

Silsesquioxanes are a class of three-dimensional oligomeric organosilane compounds from the general form ula $\left(\mathrm{RSiO}_{1.5}\right)_{\mathbf{n}}$ where $\mathrm{n}$ is an even number and $\mathrm{R}$ can be any of a large number of groups (typically, methyl, halogen, vinyl or phenyl) which are of considerable theoretical and practical interest ${ }^{1,3}$. These compounds are considerably interesting because the remarkable molecular architecture and the great structural variety that makes possible as the nature of the pendant group to be varied. Synthetic routes to silsesquioxane generally involve hydrolysis/condensation of trifunctional monomers $\mathrm{RSiX}_{3}{ }^{2}$ where $\mathrm{R}$ is chemically stable organic substitute and $\mathrm{X}$ is a highly reactive substitute such as $\mathrm{Cl}$ or alkoxy, which in the presence of water with an acid or base as a catalyst agent, leads to products generically called poly(silsesquioxanes) or silsesquioxanes (SSOs). Recently, these compounds have been used as well defined molecular model for silica surfaces ${ }^{4,6}$. Unfortunately, most of the routes employ multi step procedures using large excess of silane, long reaction times and such routes only result in very low yields of the desired products.

This paper describes the utilization of new synthetic strategies for the preparation of octakis (chloropropyldimethylsiloxy) octasilsesquioxane that are a new fam-

*e-mail: nrstradi@iq.unesp.br

Article presented at the XV CBECIMAT, Natal - RN, November/2002 ily of silsesquioxane called spherosilicates of the general formula $\left(\mathrm{Si}_{\mathrm{n}} \mathrm{O}_{3 \mathrm{n} / 2}\right)$. These compounds processing a reactive exo cage functionality which allow easy conversion into a variety of derivatives via nucleofilic substitution ${ }^{10}$ and are ideal candidates as precursor for three dimensional structure formation $^{3,7-9}$. In the recent literature Provattas ${ }^{14}$ and Dittimar ${ }^{15}$ synthesized octakis (bromopropryldimethylsiloxy) octasilsesquioxane and octa (chloropropril) silsesquioxane respectively. The first author employed the new synthetic route and the second employed sol gel method (reaction of hydrolysis of trimethoxisilane methanol/ $\mathrm{HCl}$ media), however, curiously there is no literature about Octakis (chloropropryldimethylsiloxy) octasilsesquioxane synthesis employing both routes. The new synthetic route strategy, employed in this work has not only drastically reduced reaction times and the number of steps involved, but it also has considerably improved the product yield.

The possibility of combining the properties of organic and inorganic compounds in a unique material is an old challenge that started with the beginning of the technological era. Considerable current interests are focused on the development of new hybrid composites with unusual and potentially useful properties. The first objective of this research 
was the preparation of octakis (hydridodimethylsiloxy) octasilsesquioxane and subsequent hydrosilylation with allyl chloride following its usual preliminary characterization. This material synthesized in this way serves as precursor for a series of others composites by means of substitution reactions. In this context, our interest in silsesquioxanes is the development of this type of material for electroanalytical application.

\section{Material and Methods}

\subsection{Reagents}

Allyl chloride, hexachloroplatinic acid, and $\mathrm{H}_{2} \mathrm{PtCl}_{6}$ were obtained from Aldrich. Others reagents and solvents were of analytical grade (Merck) and were used as purchased.

\subsection{Synthesis}

Octakis (hydridodimethylsiloxy) octasilsesquioxane (2) was synthesized in a two-step reaction, by following approximately the literature ${ }^{11}$.The Fig. 1 shows a scheme for the synthesis of these composites.

\subsubsection{Tetrametilammonium silicate "Octanion" (1)}

A solution of tetramethylammonium silicate was prepared by adding $1000 \mathrm{~mL}(9.5 \mathrm{~mol})$ of tetramethylammonium hydroxide in methanol $(25 \%)$ and $364 \mathrm{~mL}(20.2 \mathrm{~mol})$ of distilled water to $506 \mathrm{ml}(2.26 \mathrm{~mol})$ of tetraethoxysilicate. The resulting colorless solution was maintained over stirring for $24 \mathrm{~h}$. at room temperature.

2.2.2. Octakis (hydridodimethylsiloxy) octasilsesquioxane "Cubes" (2)

Tetramethylammonium silicate $(1000 \mathrm{~mL})$ was dropped wise to a mixture of chlorodimethylsilane $436.0(4.0 \mathrm{~mol})$ and Hexane $(2600 \mathrm{~mL})$ under a slow continuous nitrogen purge. The mixture was stirring for $4 \mathrm{~h}$. The two phases formed were separated. The hexane phase was dried with $\mathrm{Na}_{2} \mathrm{SO}_{4}$, filtered and the solvent (hexane) was removed in vacuum to give a white solid. This solid was washed with methanol and the residual methanol was removed in vacuum, and the solid resultant was dried at $80^{\circ} \mathrm{C}$ for $4 \mathrm{~h}$.

\subsubsection{Octakis (chloropropyldimethylsiloxy)}

octasilsesquioxane (3)

The hydrosilylation was accomplished by a step process as shown in Scheme 1.To a stirred solution of (2) ( $3.3 \mathrm{~g}, 9.7$ $\mathrm{mmol})$ in anhydrous diethyl ether $(15 \mathrm{~mL})$ and three drops of $1 \%$ solution of $\mathrm{H}_{2} \mathrm{PtCl}_{6}$ (Spiers catalyst) in dimethylformamide was slowly added allyl chloride $(5.97 \mathrm{~g}, 0.078 \mathrm{~mol})$ via a syringe over a period of $6 \mathrm{~h}$.

The mixture was allowed to reflux over $32 \mathrm{~h}$. The mixture was cooled, filtered through a celite bed, washed with methanol and dried in vacuum to give a white solid (yield $48.3 \%$ ). Residual allyl chloride and organic solvent were removed first under $\mathrm{N}_{2}$ stream, and then under vacuum.

\subsection{Techniques}

\subsubsection{Fourier transform infrared spectra}

Fourier transform infrared spectra were recorded on a Nicolet 5DXB FT-IR 300 spectrometer. About $600 \mathrm{mg}$ of $\mathrm{KBr}$ was ground in a mortar with a pestle, and enough solid sample was ground with $\mathrm{KBr}$ to make a $1 \mathrm{wt}$. (\%) mixture for making $\mathrm{KBr}$ pellets. After the sample was loaded, the sample chamber was purged with nitrogen for a minimum of 10 min. before data collecting. A minimum of 32 scans was collected for each sample at a resolution of $\pm 4 \mathrm{~cm}^{-1}$.

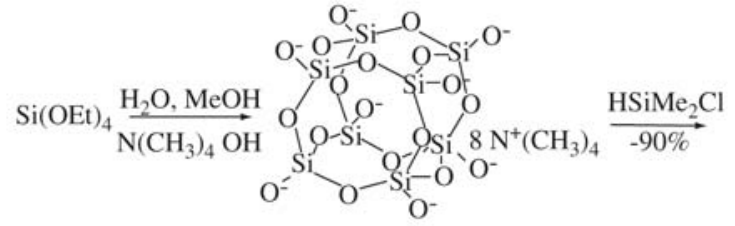

(1)

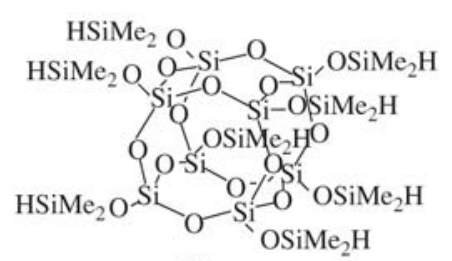

(2)

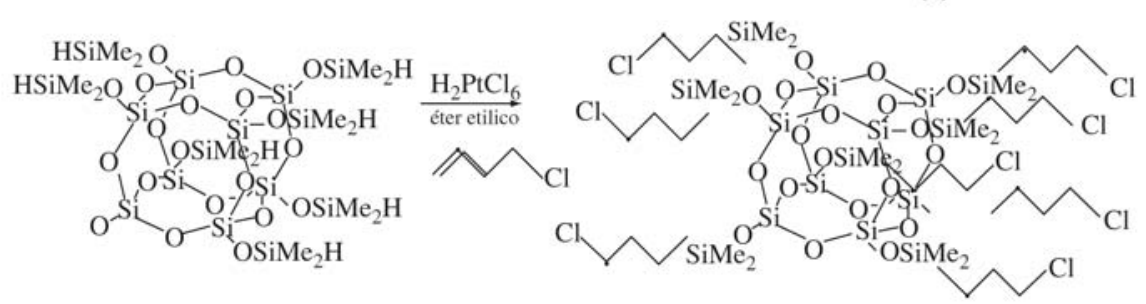

(3)

Figure 1. Scheme of synthesis of octakis (chloropropyldimethylsiloxy) octasilsesquioxane. 


\subsubsection{Nuclear Magnetic Ressonance analyses (NMR)}

All solid state analyses of ${ }^{29} \mathrm{Si}(59.5 \mathrm{MHz})$ and ${ }^{13} \mathrm{C}-\mathrm{NMR}$ $(75.4 \mathrm{MHz})$ were recorded on a Varian INOVA 300 spectrometer. The samples were packed in zirconia rotors and spun at the magic angle at $4500 \mathrm{~Hz}$, a relaxation delay of 10.0 and $6.0 \mathrm{~s}$ for ${ }^{29} \mathrm{Si}$ and ${ }^{13} \mathrm{C}$ respectively. All chemical shifts are reported in parts per million ppm $(\delta)$ with+ reference to external tetramethylsilane (TMS).

\subsubsection{Microscopy}

The scanning electronic microscopy of the materials were obtained using JEOL JSM T-300 microscope.The samples were adhered over aluminum holders and covered with a thin layer $(20-30 \mathrm{~nm})$ of gold in Sputter Coater Bal-Tec SCD-050.

\subsubsection{Thermal analyses}

The Thermogravimetry was performed with a Mettler 181 thermoanalyser. The samples $(5-10 \mathrm{mg})$ were placed in platinum samples holders. The runs were performed under nitrogen stream $(50 \mathrm{ml} / \mathrm{min})$ under still air. The samples were heated at a ramp of $10{ }^{\circ} \mathrm{C} / \mathrm{min}$ to the final temperature of $1000^{\circ} \mathrm{C}$.

\section{Results and Discussion}

The identity of 2 ( Fig. 1) was confirmed on the basis of the infrared spectrum and NMR solid state ${ }^{13} \mathrm{C}$ and ${ }^{29} \mathrm{Si}$ data, which provided consistent data near to the assigned structure reported in literature ${ }^{4,9,11}$. A sharp, strong, and assymmetric Si-O-Si stretching peak $\left[\mathrm{n}_{\mathrm{s}}(\mathrm{Si}-\mathrm{O})\right]$ at $1100 \mathrm{~cm}^{-1}$ typical of silsesquioxane cages was presented in all spectra and was used as an internal

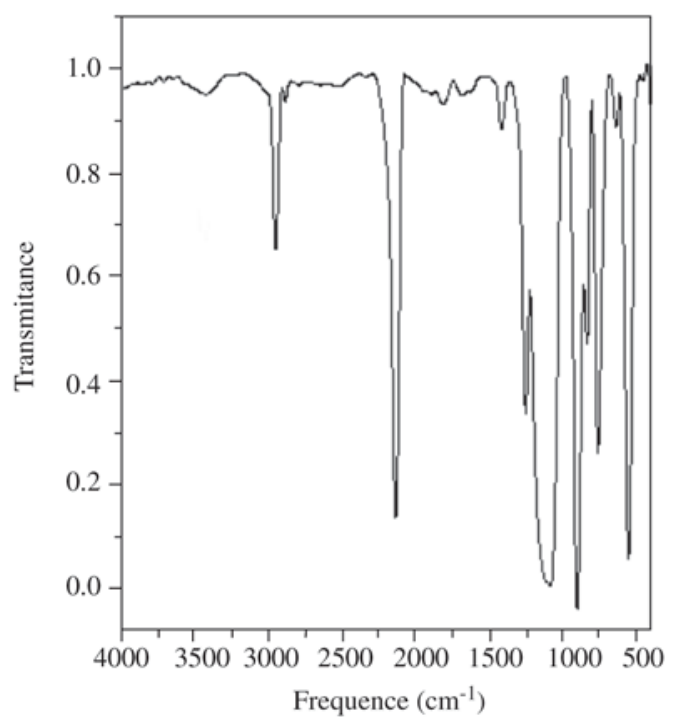

(a) reference. The consistent presence of this peak demonstrates that the initial structure is maintained during hydrosililation process. If the cube structure was degraded, one would observe a transformation to asymmetric broad peaks more typical of silica. Therefore, in agreement to the previously exposed, the $1140-1080 \mathrm{~cm}^{-1}$ region is characteristic of strong assymmetric Si-O-Si stretches in cubic architectures. Other bands can be assigned as $\mathrm{Si}-\mathrm{H}$ stretching $\left(2146 \mathrm{~cm}^{-1}\right)$, Si-H rocking (910-880 $\left.\mathrm{cm}^{-1}\right)$ and silsesquioxane skeletal deformation vibrations $\left(580-560 \mathrm{~cm}^{-1}\right)$. The main infrared absorption characteristic behavior of silsesquioxanes is summarized in Table 1. In Table 1, the selected vibrational frequencies expected for silsesquioxanes groups, are listed and ascribed ${ }^{12}$.

In the hydrosilylation of cubes, the infrared spectroscopy was used, because it indicates the progress of the reaction by monitoring the loss of Si-H absorption at $2146 \mathrm{~cm}^{-1}$ (see Fig. 2a). The Fig. 2b has shown the total absence of the Si$\mathrm{H}$ absorption band in IR spectrum at $2146 \mathrm{~cm}^{-1}$ confirmed the completeness of the hydrosililation reaction.

In order to better elucidate the siloxane chemistry ${ }^{4}$, the symbols M, D, T, Q represent $\mathrm{R}_{3} \mathrm{SiO}_{1 / 2}, \mathrm{R}_{2} \mathrm{SiO}_{2 / 2}, \mathrm{RSiO}_{3 / 2}$,

Table 1. Selected vibration frequencies for cubes.

\begin{tabular}{cc}
\hline Group functional & Wavenumber $\left(\mathrm{cm}^{-1}\right)$ \\
\hline Si-H (stretch) & 2146 \\
Si-H (roking) & 910 a 880 \\
Si-O-Si (assymmetric stretch) & 1110 a 1030 \\
OH due at $\mathrm{H}_{2} \mathrm{O}$ (free) & 3650 a 3580 \\
OH due at $\mathrm{H}_{2} \mathrm{O}$ (H- bonded) & 3550 a 3200 \\
\hline
\end{tabular}

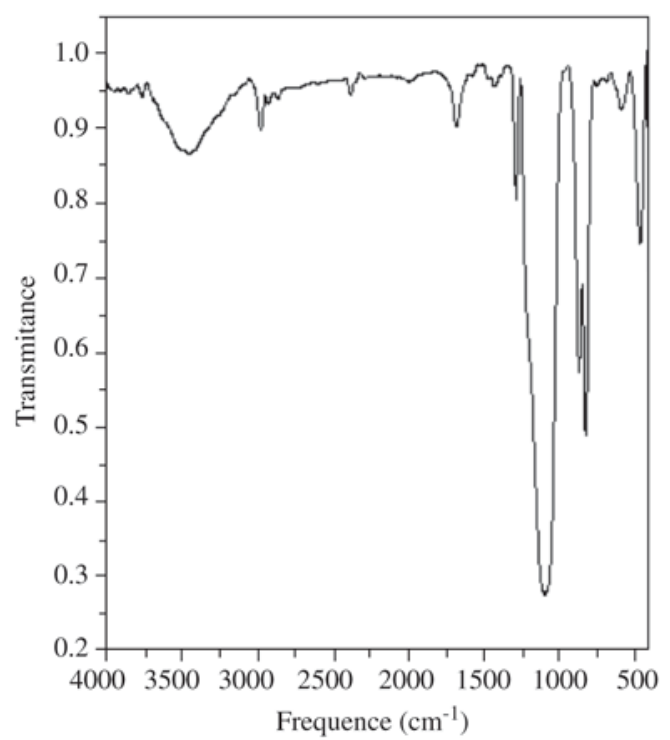

(b)

Figure 2. Infrared for composites: a) Cubes; b) octakis (chloropropyldimethylsiloxy) octasilsesquioxane. 
$\mathrm{SiO}_{4 / 2}$ units respectively. Superscripts are used to designate functional groups on the silicon. Final characterization was accomplished by ${ }^{13} \mathrm{C}$ and ${ }^{29} \mathrm{Si}$ NMR. According to the FTIR spectroscopy, the corresponding $\mathrm{Si}-\mathrm{H}$ resonance in the ${ }^{29} \mathrm{Si}-\mathrm{NMR}$ spectrum at $-3.0 \mathrm{ppm}$ Fig. 3a disappears (Fig. 3b). The three propryl groups $\alpha, \beta, \gamma$ (to the terminal silicon atom), associated to an allyl chloride, absent in cubes (Fig. 3c) were clearly seen in the ${ }^{13} \mathrm{C} \mathrm{NMR}\left(\alpha-\mathrm{CH}_{2}\right.$ at 31.8; $\beta-\mathrm{CH}_{2}$ at $37.7 ; \gamma-\mathrm{CH}_{2}$ at $50.1 \mathrm{ppm}$ ) (see Fig.3d).

Most hydrosilylations produce two products (- $\left.\mathrm{SiCH}\left(\mathrm{CH}_{3}\right) \mathrm{CH}_{2}{ }^{-}, 10-20 \%\right)$ and $\left.-\mathrm{Si}\left(\mathrm{CH}_{2}\right)_{3}-, 80-90 \%\right)$. Bassindale and Gentle ${ }^{13}$ have reported that vinyl/ $\mathrm{H}$ exchange on the silicon atom may possibly be occurring. Such vinyl/ $\mathrm{H}$ exchange will form an additional product, which would be an octopus dimmer, in which two silsesquioxane cores are jointed by ethylene linkage bridging the two cores together. In this study this idea is not supported by ${ }^{29} \mathrm{Si} \mathrm{NMR}$ due to the presence of $\mathrm{D}$ type silicon in the product ${ }^{9}$ at -18.4 ppm. Interestingly Hasegawa ${ }^{9}$ verified the presence of D sites type as subproduct of dimerization of octanion precursor, but in this study the D sites type can be associated with

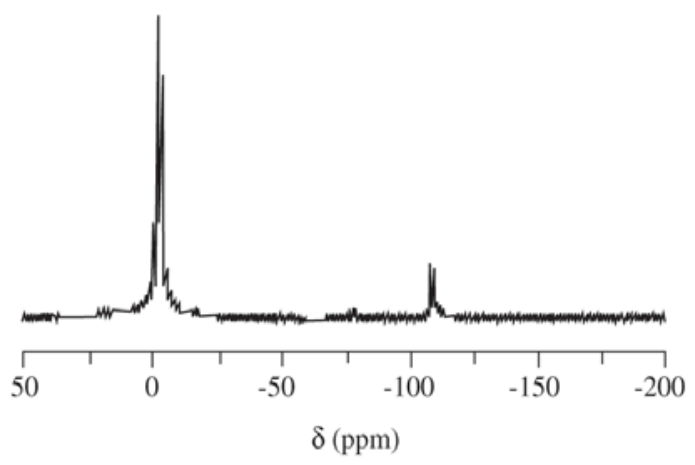

(a)

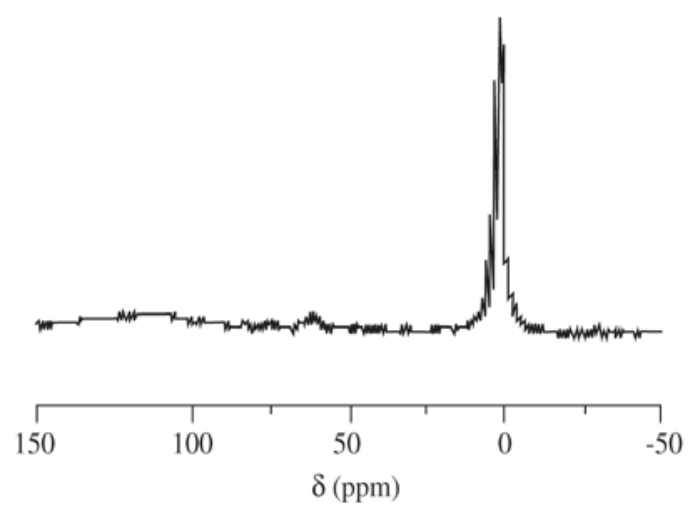

(c) sub-product formed of hydrolysis reaction of $\mathrm{Si}-\mathrm{H}$ bonding (in 2). This fact is in agreement with appreciable amount of this species exibhit by ${ }^{29} \mathrm{Si} \mathrm{NMR}$. The ${ }^{29} \mathrm{Si} \mathrm{NMR}$ spectrum of the final product, exhibits three $\mathrm{Q}$ signals for $\mathrm{Q}$ type silicon attributed at $\mathrm{Q}^{2}(-90.1), \mathrm{Q}^{3}(-100.2)$ and $\mathrm{Q}^{4}(-111.3 \mathrm{ppm})$ (Fig. 3b). The existence of these signals $\left(\mathrm{Q}^{2}\right.$ and $\left.\mathrm{Q}^{3}\right)$ beyond the last one $\left(\mathrm{Q}^{4}\right)$ means that an appreciable amount of this sub-product with open structure exists.

This assumption has led us to tentatively attribute the peak at - 90.1 and - 100.2 ppm to $\mathrm{SiO}_{2 / 2}(\mathrm{OH})_{2}$ and $\mathrm{SiO}_{3 / 2} \mathrm{OH}$ groups respectively.

Differently of analogous composite synthesized by Provattas ${ }^{14}$ no evidence by NMR spectroscopy was observed for $\mathrm{M}$ type silicon $\mathrm{M}\left(\mathrm{CH}_{2}\right)_{3} \mathrm{Cl}$. Instead, Dittimar ${ }^{15}$ have not reported in the synthesis of octa (chloropropyl) octasilsesquioxane this $M$ type silicon, but a signal at - $60 \mathrm{ppm}$ was reported.

Scanning Electronic Microscopy (SEM) measurements were performed in order to see whether the heat treatment of the cubes changes the surface.

Examination of the octacube and octakis (chloropropyl-

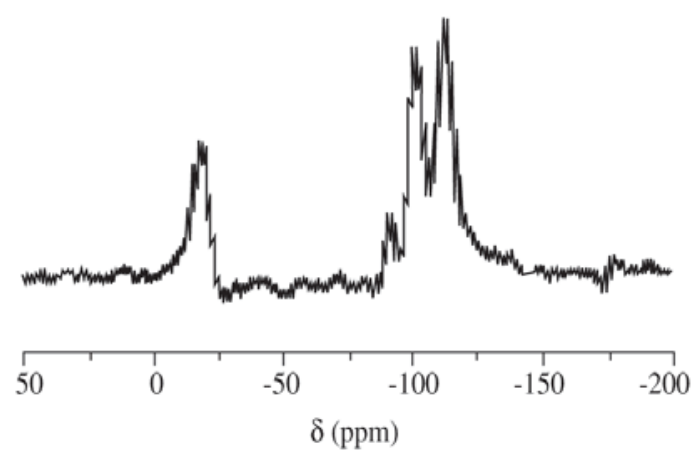

(b)

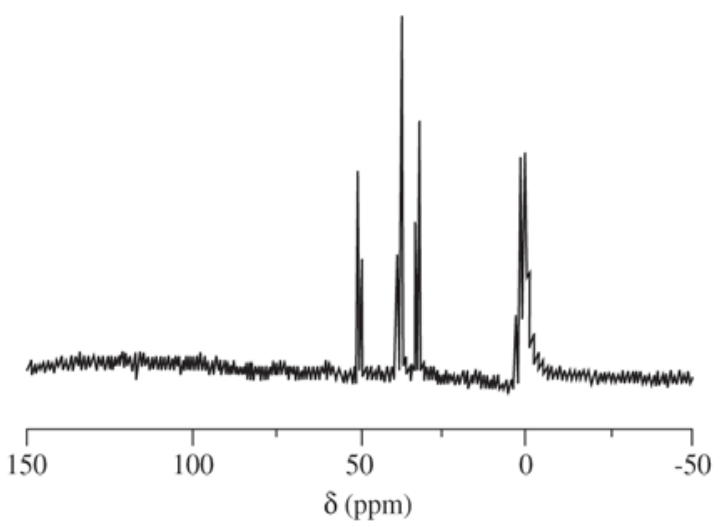

(d)

Figure 3. ${ }^{29} \mathrm{Si}$ NMR solide state for : a) cubes; b) octakis (chloropropyldimethylsiloxy) octasilsesquioxane; c) ${ }^{13} \mathrm{C}$ NMR solide state for: cubes; d) octakis (chloropropyldimethylsiloxy) octasilsesquioxane. 
dimethylsiloxy) octasilsesquioxane with scanning electronic microcopy revealed that the material precursor (cubes) is formed from aggregates of cubic particles highly porous (see Fig. 4a and 4b). After reaction with allyl chloride, a new scanning electronic microcopy exhibits the disappearance of the majority of pores (Fig. 4c).

The thermogravimetric analysis, TG, for all the composites were obtained in both nitrogen and synthetic air atmospheres. The TG curves for cubes, under synthetic air (Fig. 5a) shows that the compound is anhydrous. The first mass loss step between 172.3 and $280.6{ }^{\circ} \mathrm{C}(24.47 \%)$ may be due to the loss of counter ion with an exothermic peak at $250.5^{\circ} \mathrm{C}$. The mass loss between 281.2 and $824.3^{\circ} \mathrm{C}(8.41 \%)$ can be ascribed to the decomposition of the residual $\mathrm{Si}_{-} \mathrm{CH}_{3}$ groups, and octanion cage corresponding to the exothermic peak at $429.8{ }^{\circ} \mathrm{C}$ with $\mathrm{SiO}_{2}$ formation as oxide residue at $1200{ }^{\circ} \mathrm{C}$. Under nitrogen atmosphere (Fig. 5a), the cubes partially sublime ${ }^{7}(95.70 \%)$ between 187.7 and $280.1^{\circ} \mathrm{C}$ without marked decomposition showing an endothermic peak at $264.1{ }^{\circ} \mathrm{C}$ and a carbonaceous residue at $350.0^{\circ} \mathrm{C}$.

The Fig. 5b, shows the behavior of $\left[\left(\mathrm{ClCH}_{2} \mathrm{CH}_{2} \mathrm{CH}_{2} \mathrm{Me}_{2}-\right.\right.$ $\left.\mathrm{SiO}) \mathrm{SiO}_{15}\right]_{8}$, studied with termogravimetric analysis under nitrogen and synthetic air atmospheres.

Under inert and air atmospheres the decomposition starts at about $84^{\circ} \mathrm{C}$ and beyond $800{ }^{\circ} \mathrm{C}$ a leveling of weight loss is observed.

Three weight losses recorded up to the end were verified for both atmospheres. The first weight loss was of 5\% ascribed to the residual water. The second weight loss (4.8\%) starts at $135{ }^{\circ} \mathrm{C}$ ascribed to the residual organic compounds included in the products decomposition. The third decomposition, which starts at $402{ }^{\circ} \mathrm{C}$ with weight loss of $9.2 \%$ was ascribed to the decomposition of residual $\mathrm{Si}-\mathrm{CH}_{3}$. The total of weight losses recorded up to the end of these decompositions were $18 \%$.

As shown in Fig. 5b, the composite is more stable in nitrogen than air, which is similar as the analogue thermal degradation behavior ${ }^{16}$. Under nitrogen, the thermal cleavage of $\mathrm{C}-\mathrm{Si}$ and $\mathrm{C}-\mathrm{C}$ bonds result from allyl chain reaction is more stable even at higher temperature or just decomposes very slowly ${ }^{17}$, as a result the residue $\left(\mathrm{SiO}_{2}\right.$ mainly) is higher. Nevertheless, under air, both the thermal cleavage and oxidizing of $\mathrm{Si}-\mathrm{R}\left(\mathrm{R}=\left(\mathrm{CH}_{2}\right)_{3} \mathrm{Cl}\right)$ is influenced by air oxygen and residue is lower.

\section{Conclusion}

Octakis (hydrodimethylsiloxy) octasilsesquioxane was hydrosilylated with allyl chloride using Spiers catalyst $\left(\mathrm{H}_{2} \mathrm{PtCl}_{6}\right)$ This reaction was monitored using IR spectroscopy. This material was characterized by FT-IR and solid state RMN and there is an evidence of hydrolysis reaction in synthesis process. The presence of allyl chloride substitutes in octameric
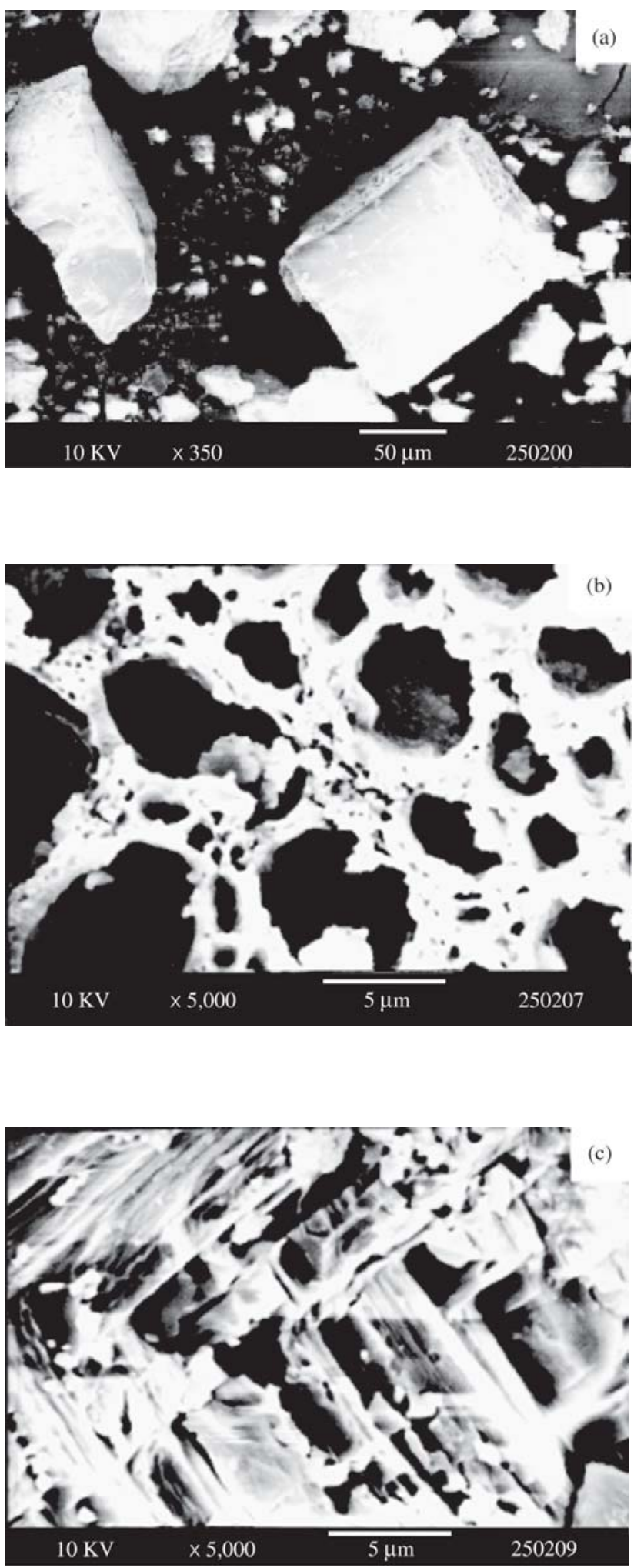

Figure 4. Scanning electron micrograph of: a) cubes, $\times 350$; b) cubes, $\times 5000 ;$ c) octakis (chloropropyldimethylsiloxy) octasilsesquioxane $\times 5000$. 


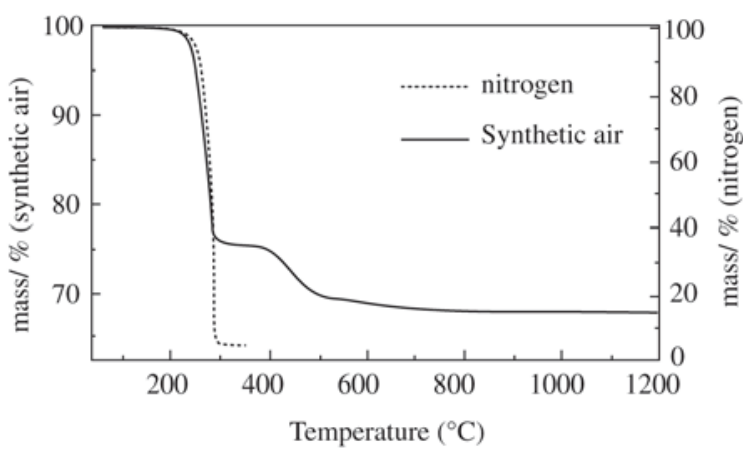

(a)

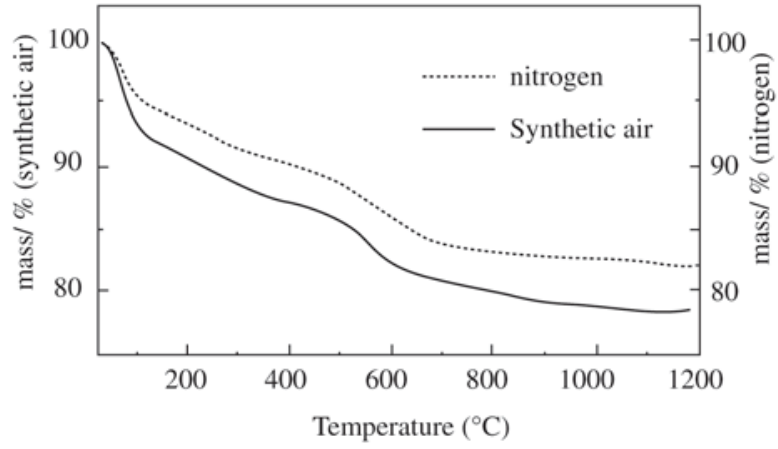

(b)

Figure 5. a) TG curves for cubes; b) $\left[\left(\mathrm{ClCH}_{2} \mathrm{CH}_{2} \mathrm{CH}_{2} \mathrm{Me}_{2}-\mathrm{SiO}\right) \mathrm{SiO}_{1.5}\right]_{8}$, under atmospheres: synthetic air $\left(-\frac{}{\longrightarrow}\right)$ and nitrogen $(\cdots \ldots \ldots \ldots \ldots . .$.$) .$

cube, as monomer or dimmer confers a relative thermal stability to the material. The material could be employed as starting reagent for synthesis of hybrid compounds.

\section{Acknowledgement}

Financial support for this research was supplied by Fundação de Amparo à Pesquisa do Estado de São Paulo (FAPESP) (Proc. 01/04494-0).

\section{References}

1. Baney, R.H.; Itoh, M.; Sakakibara, A.; Suzuki, T. Chem. Rev., v. 95, p. 1409-1430 1995.

2. Voronkov, M.G.; Lavrentyev, V.L. Top. Curr. Chem., v. 102, p. 199-236, 1982.

3. Zhang, C.; Laine, R.M. J. Organomet. Chem., v. 521, 189-201, 1996.

4. Provatas, A.; Matisons, J.G. Trends. Polym. Sci., p. 327332, 1997.

5. Feher, F.J.; Newman, D.A.; Walzer J.F. J. Am. Chem. Soc., v. 111, p. 1741-1748, 1989.

6. Kadama, K.; Sugimura, M.; Yuda H. Japanese Patent, n. 6, v. 271 p. 771.

7. Harrison, P.G. J. Organomet. Chem., v. 542, p. 141-183, 1997.

8. Hasegawa, I.; Motojima, S. J. Organomet. Chem., v. 441, p. 373-380, 1992.

9. Hasegawa, I. Trends in Organometallic Chemistry, v. 1, p. 131-142,1994.

10. Lucke S.; K- Langner, K. Applied Surface Science, v. 144, p. 713- 715, 1999.

11. Laine, R.M.; Asuncion, M.; Baliat, S.N.; Dias Filho N.L.; Harcup J.; Sutorik, A.C.; Viculis, L.; Yee, A.F.; Zhang, C.; Zhu, Q. "Organic/Inorganic Molecular Hybrid Materials From Cubic Silsesquioxanes," in Organic/Inorganic Hybrid Materials, MRS Symp. Ser., Klein, L., De Guire, M.; Lorraine,F.; Mark, J. v. 576, 2000.

12. Denq, B.L.; Hu, Y.; Chen, I.; Chiu, W.; Wu, T. J. Appl. Polym. Sci., v. 74, p. 229-237, 1999.

13. Bassindale, A.R.; Gentle,T. J. Organomet. Chem,. v. 521, p. 391-393, 1996.

14. Provatas, A.; Luft, M.; Mu, J.C.; White, A.L.; Matisons, J.G.; Skelton, B.W. J. Organomet. Chem., v. 565, p. 159164, 1998.

15. Dittmar, U.; Hendan, B.J.; Florke, U.; Marsmann, H.C. J.Organomet.Chem., v. 489, p. 185-194, 1995.

16. Morán M.; C.M. Casado, I. Cuadrado, Organomettalics, v. 12, p. 4327-4333,1993.

17. Wang J.; He, C.; Lin, Y.; Chung T.S. Termochimica Acta., v. 381, p. 83-92, 2002. 